\title{
HOMENS E MULHERES FALANDO EM GENOCÍDIO: A EXPERIÊNCIA IMPERIALISTA ALEMÃ (1884-1945)
}

\author{
Men and Women Talking about Genocide: Imperialist \\ Experiences among Germans (1884-1945)
}

Marion Brepohl de Magalhães*

\begin{abstract}
RESUMO
Este artigo pretende analisar algumas experiências coloniais alemãs promovidas por homens de negócios e agentes coloniais que ocuparam uma razoável porção territorial na África, procurando detectar algumas semelhanças ou mesmo identificações entre estas práticas e aquelas praticadas à época do nacional-socialismo.
\end{abstract}

Palavras-chave: imperialismo; genocídio; herreros.

\begin{abstract}
Some German colonial experiences through which businessmen and colonial agents occupied a substantial portion of African territory are examined in this article. We also identify similarities between these practices and those that were proper to National Socialism, stressing that some of them were actually nazi.
\end{abstract}

Key words: Imperialism; genocide; herreros.

Até bem pouco tempo, o Imperialismo alemão na África foi pouco explorado tanto como um tema relevante para a História da própria Alemanha como entre os estudiosos que se dedicaram e se dedicam à História da África. Mesmo para os autores interessados em compreender o Imperialismo enquanto fenômeno constitutivo do mundo moderno, apenas a Alemanha

* Professora Associada do Departamento de História da Universidade Federal do Paraná Bolsista do Conselho Nacional de Desenvolvimento Científico e Tecnológico - CNPq. 
Nazista era citada, para colocar em evidência o principal exemplo do expansionismo no interior da própria Europa, praticado por aquele governo em nome da ampliação do Lebensraum (espaço vital).

Diversas razões podem explicar esta ausência: a primeira delas reside na alegada efemeridade da presença alemã em solo africano; afinal, além de tardia a corrida alemã para a África (o que lhe custou a ocupação de territórios menos estratégicos do ponto de vista econômico e militar), ao final da Primeira Guerra todas as suas colônias são tomadas por outras potências imperialistas. Alega-se também que a ocupação territorial em ultramar foi preterida pelo chanceler Otto Von Bismarck por considerar onerosas a manutenção de um exército de defesa e uma burocracia nos territórios conquistados, preferindo eleger zonas de influência em regiões onde as mercadorias alemãs pudessem ser exportadas com alta lucratividade devido às vantagens comparativas que seus produtos propiciavam, algo que já se fazia entrever nas relações comerciais com as Américas ${ }^{1}$. De resto, a emigração de alemães para outros países soava a muitos políticos da época como um mercado consumidor em potencial, além da vantagem de se "exportar" a questão social advinda da concentração urbana e do desemprego.

Uma voz dissonante relativamente a estas interpretações foi a de Hannah Arendt, em seu livro Origens do totalitarismo ${ }^{2}$, escrito na década de 50 do século XX, senão até um pouco antes: já em 1946, num pequeno artigo jornalístico ${ }^{3}$, ela identifica as conexões entre racismo e imperialismo, bem como suas inter-relações com o genocídio e com a formação da elite nazista.

Suas ideias não foram prontamente aceitas. Primeiro, pela escassez ou mesmo inexistência de debates sobre o colonialismo na África no ambiente acadêmico europeu do pós-guerra. Segundo, porque muitos intelectuais, principalmente aqueles filiados às correntes marxistas, entenderam tal análise como determinista e pouco atenta aos interesses econômicos então em jogo. Sobretudo porque, ao sugerir que a tentação totalitária atingiu toda a Europa e não apenas a Alemanha, muitas de suas teses foram, em boa medida, engavetadas.

1 A este respeito, ver: BREPOHL DE MAGALHÃES, M. D. Os pangermanistas na Argentina, no Brasil e no Chile. In: DAYRELL; YOKOI (Orgs.). América Latina Contemporânea: desafios e perspectivas. São Paulo: Expressão e Cultura/EDUSP, 1996, p. 329-344, e WEHLER, U. Bismarck's imperialism - 1862-1890. Past and Present, n. 48, p. 119-132, August/1970.

2 São Paulo: Companhia das Letras, 1989.

3 ARENDT, Hannah. Imperialism: road to suicide. In: Commentary. American Jewisch Comitee, 1946. 
Por outro lado, a literatura pós-colonial, ao procurar reagir às tendências eurocentristas de interpretação da África, deixou ao relento, por vezes, temas cuja documentação e enunciados se encontravam na Metrópole, em favor da história do colonizado: não por acaso, são numerosas neste conjunto as contribuições de antropólogos que buscam rastrear, no detalhe, o cotidiano e o sistema de valores das populações ex-colonizadas, comunidades minoritárias e em vias de perda de identidade, numa tentativa de contestar o eurocentrismo, bem como os conceitos a partir daí formulados.

Estudos mais recentes, todavia, procuram adotar outra direção: atentos à dialética colonizadores/colonizados, bem como ao fato de ter o ato imperialista afetado não apenas as zonas ocupadas, mas também a vida do homem dos Impérios ${ }^{4}$, evitam a leitura binária Primeiro Mundo/Terceiro Mundo e sua alteridade inexorável, tributária, em boa medida, do linguist turn e do visual turn.

Decorre daí que outras indagações são propostas, como, por exemplo, as estratégias de cooptação de nativos no processo de estruturação da burocracia colonial e mesmo da ideologia racista; as intersecções entre as doutrinas racialistas que explicavam o caráter dos nativos de ultramar e outros segmentos da população europeia; as afirmações de diversos movimentos nacionalistas que se valem de paradigmas étnicos como critério identitário, movimentos de esquerda ou de direita, emancipacionistas ou expansionistas, com objetivos precipuamente econômicos ou, em outra ponta, precipuamente religiosos; finalmente, contempla estas indagações a constatação sobre a necessidade de se levar em conta os imperativos da economia e da ação política no delineamento da história.

Este artigo, que tem por objetivo analisar alguns aspectos do Imperialismo alemão e suas conexões com o nacional-socialismo, a partir de uma perspectiva transnacional e transcontinental, inscreve-se neste rol de publicações.

Pretendo demonstrar, ainda que sem sistematizar todas as fontes que arrolei (pois a pesquisa ainda está em curso), a emergência de uma literatura panfletária, que antepõe ou entrecruza o bom selvagem ou o exótico (ainda idilicamente presente em muitas imagens europeias sobre o outro

4 Dentre os diversos estudos com este enfoque, destaquem-se o de Mary Pratt (Os olhos do império. Bauru: EDUSC, 1999) e o de Edward Said (Orientalismo. São Paulo: Companhia das Letras, 1996). 
até então) com o nativo inferiorizado e brutal, o segundo, gradativamente, fazendo desaparecer o primeiro; algo que sempre esteve ali, mas que num determinado momento adquire visibilidade: a hipótese do genocídio.

\section{África e Auschwitz}

Em junho de 1986, Ernest Nolte publicou no semanário Frankfurter Allgemeine Zeitung (FAZ) um artigo intitulado "O passado que não quer passar", cujo conteúdo seria o estopim para o início à querela dos historiadores (Historikerstreit) ${ }^{5}$, a qual ganhou ampla visibilidade nos meios de comunicação. Tratou-se de um debate bastante acirrado sobre a política da memória, incitado, principalmente, pela imediata intervenção de Jürgen Habermas, que enxergou nas afirmações de Nolte um dos muitos sintomas da tendência neoconservadora que orientava o ambiente político e cultural de então, favorecendo-se, inclusive, o questionamento da tese da singularidade dos crimes nazistas, notadamente aqueles praticados nos campos de concentração.

Para Nolte, os crimes nazistas não podiam ser interpretados como um fato histórico singular, uma vez que eram consequência de uma reação defensiva contra os crimes soviéticos; o nacional-socialismo só teria surgido, portanto, em resposta ao genocídio de classe e à barbárie asiática dos bolchevistas. Nolte cita ainda a gaiola de ratos, espécie de tortura chinesa, elaborada esteticamente por Georges Orwell em seu livro 1984', como uma das formas preferidas de tortura empregadas ao longo da Revolução Russa. Em seu polêmico livro, escrito em $1963^{7}$, ele já houvera detalhado suas ponderações sobre os precedentes bolchevistas no ato de tortura e genocídio: Gulag reeditava uma prática a um só tempo asiática e de esquerda, passando por Babeuf e chegando até o regime Pol Pot, do Camboja, tanto quanto aos movimentos ingleses do século XIX que lutavam pela reforma agrária.

5 Sobre a querela dos historiadores, ver: Dossiê História e nazismo. Novos Estudos: CEBRAP, p. 3-27, São Paulo, outubro de 1989.

6 Neste livro, Smith, o protagonista do romance, é compelido a renegar sua namorada porque seus torturadores acoplam uma gaiola em seu rosto, onde está enjaulado um rato faminto, pronto a atacar (ORWELL, G. 1984. São Paulo: Companhia das Letras, 1984).

7 Der Faschismus in seiner Epoche. München: Pipper Verlag, 1989. 
Retornando ao artigo jornalístico de 1986, mencione-se que Nolte cita ainda o exemplo do genocídio armênio, ocorrido em Erzerum, Turquia, em 1915, quando, além do genocídio, foram praticadas torturas tão ou mais violentas do que aquelas ocorridas na Alemanha Nazista.

Trata-se, sem dúvida, de um artigo engajado, que postulava ter a Alemanha o direito à sua identidade, ou mais, ao orgulho nacional, e que essa identidade teria necessariamente de associar-se à unidade (leia-se reunificação), a qual Reagan, em visita à Alemanha neste mesmo ano, para comemorar os 40 anos do final da Segunda Guerra, reclamou a Gorbatschow.

Não façamos, contudo, uma injustiça a Ernest Nolte. Ele não é, de maneira alguma, um militante. É um intelectual conservador, principalmente se o pensamos no contexto da Guerra Fria; outrossim, sua pesquisa é cuidadosa e detalhada, em busca do entendimento da violência na política e, em especial, para o que nos interessa aqui: do genocídio.

Ao genocídio de um povo como o armênio - o qual ele identifica como o primeiro perpetrado no século XX - ele associa o genocídio de classe, ou seja, os massacres e torturas praticados na Rússia durante a Revolução. Essa é uma mistura complicada: em que pese a luta de raças e a luta de classes terem sido palavras-chave para a violência em ambos os sistemas totalitários europeus, o genocídio tem a sua própria história, a sua própria lógica, a sua própria definição: diz respeito à aniquilação do indesejável e não do oponente. Isso não é um detalhe, afinal o oponente pode se arrepender ou fugir para o anonimato; códigos genéticos não são, senão nos sonhos de biólogos do século XXI, uma condição de per se.

Outra questão, entretanto, é mais polêmica e quiçá mais desconcertante para um historiador alemão: ele comenta que o genocídio armênio foi o primeiro praticado no século XX e trata da tortura como uma tática de esquerda. Mas o primeiro genocídio do século XX não foi este, tampouco praticado por asiáticos e/ou pela esquerda: o primeiro genocídio do século XX foi alemão, perpetrado pelas tropas do agente colonial Lothar Von Trotha, na região de Omaheke, contra o povo herrero.

Destaque-se que o método empregado era particularmente cruel. As tribos Herrero eram levadas pelas tropas alemãs ao deserto Omaheke, onde todos os poços haviam sido envenenados. Os soldados tinham ordens de matar todos - homens, mulheres, crianças - que tentassem fugir do deserto. 
Os poucos que restaram vivos - cerca de $20 \%$ da população foram internados em campos de concentração, onde as mulheres foram tratadas como escravas sexuais e os homens, utilizados como cobaias para experiências científicas.

Quando pesquisamos como historiadores estes fatos, concluímos que aí se constituiu um espaço legalizado de brutalidade, passível de ser conhecido por uma farta documentação de época, a descrever seus horrores, devidamente difundidos até pelos perpetradores do ato genocida. Por isso, não se pode considerar tal episódio como um acidente doméstico, inerente a uma administração colonial composta de homens e mulheres despreparados para a exploração econômica, administração que pouco se relacionava com a metrópole. Foi, como outros massacres, um acontecimento europeu, que se vincula, e isso procuraremos demonstrar, com uma lógica que se estenderá a todo o planeta: a racialização das sociedades.

\section{A ocupação de regiões africanas pelos alemães}

O Imperialismo alemão na África se desenvolve com algumas especificidades que o distingue daqueles praticados por outras nações e isso precisa ser compreendido até para colocar em relevo a tensão entre colonizadores, os governos da metrópole e a ação dos nativos.

Como mencionamos, Otto Von Bismarck não tinha como prioridade a política de conquista de territórios na África. Mas ele teve que enfrentar diversas reivindicações de forças políticas conservadoras representadas no parlamento nos anos 1884 e 1887, defendendo a política colonial, em nome do alargamento do espaço vital (Lebensraum) e da necessidade de concorrer com o poderio econômico inglês, cujo sucesso era interpretado como resultante de suas práticas expansionistas.

Segundo Strandmann, Bismarck acabou por ceder à política imperialista muito mais por motivos eleitorais do que econômicos ${ }^{8}$. O Partido Social Democrata estava em franco processo de crescimento (em 1887 atinge

8 STRANDMANN, H. Germany's colonial expansion under Bismarck. Past and Present, n. 42 , p. $140-159,1972$. 
o coeficiente de $17 \%$ dos votos); a concentração fundiária provocava um rápido e intenso êxodo rural; e a industrialização em grande escala ameaçava os pequenos negociantes, os quais passariam a enxergar com alguma simpatia as teses dos defensores do expansionismo alemão.

Para Liebknecht, do Partido Social Democrata, a política colonial era uma nuvem de fumaça que ocultava as contradições inerentes ao capitalismo: o que se pretendia, na verdade, era exportar ou mesmo deportar a questão social"; já para o deputado Vollmar, a "superprodução só seria atenuada com reformas econômicas. Pois em países modernos, o melhor mercado é o mercado interno, que se faz acompanhar pela livre opinião de um povo soberano"10. Já o desenvolvimento de mecanismos que favorecessem o comércio externo era aceito tanto pelos socialistas como pelos liberais.

Em geral, os social-democratas enxergavam na política colonial uma estratégia de propaganda ideológica para desviar as atenções do povo sobre a necessidade de reformas. E estavam certos. De maneira cada vez mais intensa e estridente, nacionalistas de todos os matizes difundiam a propaganda em favor da expansão colonial como estratégia para acabar com o desemprego no interior da Alemanha, tanto quanto para cumprir o destino civilizatório - termos emprestados da Inglaterra, cujo governo invejavam - e, ao mesmo tempo, pretendiam sobrepor-se na concorrência pela dominação do mercado mundial.

Assim sendo, para pressionar o governo, é criada a Associação Colonial Alemã. Por conta de suas articulações, o Reich assumiu em 1883 a proteção da zona do Sudoeste Africano, onde o negociante de Bremen, Ludertiz, comprara terrenos no ano anterior. Em seguida, o viajante e explorador Gustav Nachtigal conseguiu para o Reich, em 1884, os direitos de soberania sobre o Togo (Togolândia) e os Camarões. Por fim, em 1885, fundou-se a Sociedade Alemã Oeste-Africana, sob a liderança do agente colonial Carl Peters, a qual comprou grandes faixas de terra do sultão de Zanzibar (Tanganica). Ruanda e Burundi só foram entregues à Alemanha em 1890, numa conferência em Bruxelas, em troca de Uganda e da ilha de Heligoland. No entanto, as fronteiras desta colônia - que incluíam também alguns pequenos reinos das margens do Lago Vitória - só foram definidas em 1900.

$175-6$

9 WEHLER, U. Bismarck und der Imperialismus. Köln \& Berlin: Kiepenheuer, 1969. p.

10 Apud WEHLER, Ibidem, p. 176. 


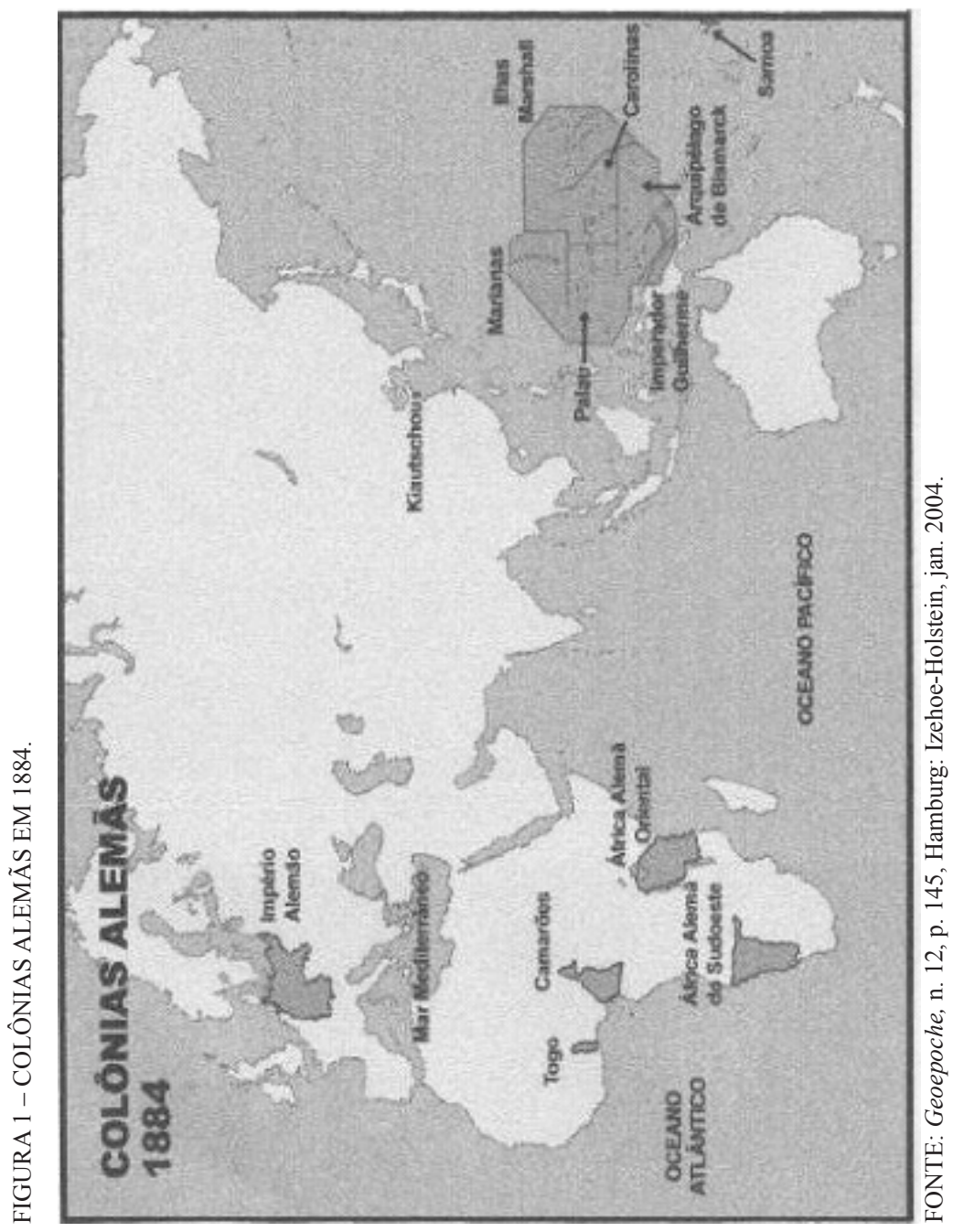


Dada esta conjuntura, aqui rapidamente comentada, pode-se constatar que a expansão colonial alemã foi objeto muito mais da iniciativa privada do que dos poderes públicos. Isso explica, em parte, muitas das arbitrariedades praticadas contra os nativos e mesmo em relação às fronteiras (de resto, sempre mal traçadas) das colônias que pertencessem a outros países europeus.

Esta a primeira diferença em relação às outras potências imperialistas. A segunda diz respeito à tensão provocada pelo jogo político partidário: sim, porque conquanto a violência tenha recorrentemente acompanhado tais práticas coloniais (não apenas as alemãs, aliás), há que se mencionar que as esquerdas e os liberais sempre fizeram franca oposição ao comportamento da burocracia colonial na África. Não apenas por seu interesse em oporem-se eleitoralmente às plataformas políticas que defendiam o expansionismo como meio de se estancar a questão social, mas também, com relativa rapidez, observamos que a ênfase passará a incidir sobre outra questão, qual fosse, a violência contra os nativos. Afinal, aquelas regiões, segundo os liberais e socialistas, uma vez conquistadas, pertenciam ao Estado alemão, devendo ser seus habitantes tratados como cidadãos. Por estas razões, diversos encaminhamentos políticos e institucionais foram reclamados com o intuito de propugnar, junto ao parlamento, a elaboração de medidas legais que garantissem direitos aos nativos.

Todavia, os agentes coloniais se viam como os únicos e efetivos senhores das colônias, o que pode ser ilustrado, segundo Bettina Zurstrassen, pelo leitmotiv: "Deus está no céu, o rei bem longe e eu estou aqui""1. Dissimulação, corrupção e protestos por parte da burocracia colonial foram as respostas aos argumentos em favor dos nativos, o que cooperou, como veremos a seguir, para uma radicalização discursiva cada vez mais intensa, apresentada não pela aporia esquerda versus direita, mas em torno daquilo que a escritora Frieda von Bülow denominou como a "espacialização da diferença", ou seja, a legitimação do racialismo como critério de governo.

Cito Frieda von Bülow, dentre outros atores sociais neste processo, por ter sido ela uma importante articuladora das relações entre entidades

11 No original: "Gott ist im Himmel, der König weit fort und ich bin hier". Apud ZURSTRASSEN, B. Die Steuerung und Kontrolle der kolonialen Verwaltung und ihrer Beamter am Beisspiel des Schutzgebietes Togo; 1884-1914. München: Inauguraldissertation zur Erlangung des Grades eines Doktors der Philosophie. (s/d). 
privadas conservadoras na Alemanha e as colônias. Foi uma importante defensora do racialismo, entusiasta da política colonial, membro da Liga Pangermânica, antissemita, colaboradora da Liga Feminina em prol da colonização (a qual providenciava a emigração de moças brancas para se casarem com os colonizadores), apaixonada pelo principal agente colonial alemão, Carl Peters, com quem manteve um romance quando de sua estada na África Alemã Oriental (1885-1887) ${ }^{12}$. Seus escritos representam, segundo Elisa von Joeden-Forgey, a virada racialista da política colonial alemã: conforme a autora, se nos primeiros 15 anos a linguagem dominante da administração colonial deixava-se orientar pelas noção de civilização, senso missionário e inclusão dos nativos como membros do Reich, a partir do início do século XX, em resposta às denúncias dos social-democratas, as doutrinas racistas passam a constituir o elemento estruturante das relações entre colonizadores e colonizados ${ }^{13}$. Isso se deveu principalmente à institucionalização da "Lei dos Nativos", que previa a possibilidade de aquisição de cidadania por parte dos homens de cor. Enquanto não se naturalizavam, deviam ficar sob a proteção do governo local, seguindo-se os direitos costumeiros de cada cultura local.

Ainda que, na prática, os "direitos dos nativos" (Eingeborenerechte) não representassem qualquer garantia que impedisse a administração local de surrá-los, de tratá-los como semiescravos, de excluí-los de territórios, a simples possibilidade de se tornarem cidadãos alemães e mesmo de se casarem com brancos ou brancas açulou os nervos dos membros da Liga Pangermânica, que passaram a arreglar para si o que eles mesmos denominariam como "luta de raças" (Rassenkampf).

Com isto,

Ao incluir os Eingeborene no reino do estado soberano e seu monopólio da violência, ao mesmo tempo em que excluem-lhes quaisquer instituições e tradições que pudessem protegê-los, o estado alemão criou, na prática, ainda que não intencionalmente,

12 A respeito desta intelectual, ver: www.fembio.org/biographie.php/frau/biographie/friedavon-bulow (pesquisa realizada em 19 de setembro de 2010), e OLDEN, Balder. Ich Bin ich. Berlin: Deutsche Verlags-Aktiengesellschaft, 1927.

13 JOEDEN-FORGEY, E. Race, power, freedom and the democracy of terror in german racialist thought. In: KING, R.; STONE, D. (Org.). Hannah Arendt and the uses of History: imperialism, nation, race and genocide. New York: Berghahn Books, p. 20-37. Tradução livre da autora. 
uma categoria de pessoas potencialmente genocidas - pessoas que existiam inteiramente ao largo de uma comunidade em que houvesse obrigações morais; [...] para elas, muitos assassinatos não eram tecnicamente ilegais ${ }^{14}$.

Para muitos membros da Liga Pangermânica, o genocídio não era condenável; condenável era a falta de critérios para o castigo, a tortura ou o assassinato. Eu diria mais: o genocídio, como possibilidade, podia e devia levar em conta também o uso arbitrário do corpo deste outro, que não era visto como opositor ou mesmo estrangeiro, mas como inferior e potencialmente passível de contagiar os brancos, uma vez que, seguindo fielmente as palavras de Gobineau, "o sangue ruim podia estragar o sangue bom", preceito utilizado intensamente pela literatura panfletária e pseudocientífica das sociedades coloniais, o que prepara a desindividualização e desumanização dos nativos, como veremos a seguir.

\section{Os principais temas da literatura panfletária}

Observemos agora alguns exemplos do poder de persuasão desta literatura no que se refere à racialização da experiência colonial.

Em um artigo de 1887, noticia-se em Portugal, com indisfarçável admiração, que tão logo as possessões de Camarões foram adquiridas pelo governo alemão, as importações aumentaram de maneira muito significativa (de 8,6 milhões de marcos em 1882 para 14,3 milhões em 1884). Quanto às exportações, elevaram-se de 44,277 toneladas, em 1883 , para 56,104 toneladas brutas em 1885 .

Segundo a opinião do jornal,

Os alemães dão, por ordem de importância, genebra, rum, carvão, sal, arroz, pólvora, licores e aguardentes, madeiras de construção. Espalham naqueles povos selvagens [...] os bene-

14 Ibidem, p. 24. Todas as demais citações de textos em língua alemã são vertidas em português pela autora do artigo. 


\section{FIGURA2 - FRIEDA VON BÜLOW, QUE, À ÉPOCA DA PRESENÇA DE CARL PETERS NA ÁFRICA, CRIOU O PRIMEIRO HOSPITAL, PREPARA-SE PARA SUA VIAGEM E TOMA AULAS DE TIRO.}

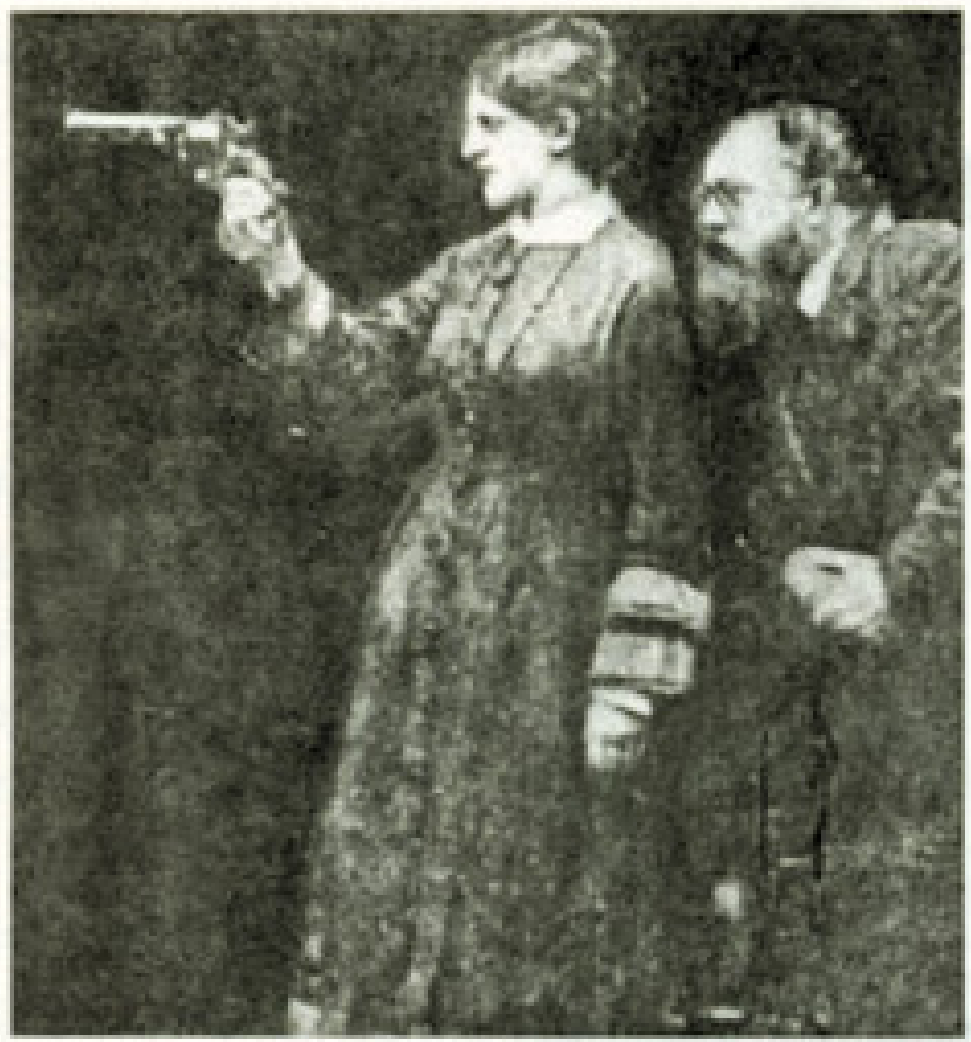

Frieda voe Bulow, die aur Zeil Dr. Karl Petere die erabea Krankensialionen in Dabifika errichtete, bereitet sich auf die Alrikalabrt vor usd nimut Bhirbunterricht.

FONTE: www.ezakwantu.com/gallery/herrero

Pesquisa realizada em 15 de outubro de 2009. 
fícios da civilização sob a forma de aguardentes falsificadas, de uniformes que já não se usam e de vidrilhos fora de moda. Em troca destes artigos recebem nozes oleaginosas, óleo de palma, marfim e cauchu ${ }^{15}$.

O texto tece outros comentários elogiosos aos exploradores alemães, mas o que nos interessa observar é a prática de escambo aí promovida, com ênfase na introdução de bebidas alcoólicas, prática altamente condenada pelos missionários, encarregados, por lei, de alfabetizar os nativos.

Sobre o corpo do nativo, Carl Peters também nos traz uma ideia sobre sua inferioridade, mas principalmente, e talvez por isso mesmo, sua utilidade: segundo ele, a população africana é dotada pela natureza de força muscular muito resistente, estando apta a exercer trabalho braçal como nenhum outro povo do mundo. Mas, devido à agradável condição de vida nos trópicos, as pessoas não têm ali um impulso interno para o trabalho. Por essas razões, torna-se necessário importar-se mão de obra para preencher essa falta. Para que este mal seja remediado, recomenda um regime de trabalho que, em troca da proteção militar que os estados dão aos territórios africanos, os negros ${ }^{16}$ trabalhem para o estado. Não seria prejudicial aos negros que, por alguns anos, tivessem de servir ao Estado, assim como os cidadãos da Alemanha, França e Rússia, que pagam impostos e prestam o serviço militar ${ }^{17}$.

Também os judeus não escapam à atenção do agente: entende que, para resolver o problema dos judeus que foram expulsos da Rússia, devido aos progroms, eles poderiam ocupar territórios alemães da África, uma vez que

Estamos num período de movimentos nacionalistas; neste sentido, o movimento sionista não é senão um movimento desta natureza. [...] Argumentam que o movimento sionista é um movimento confessional, uma vez que há judeus alemães, ingleses etc., mas isso é somente porque houve a diáspora [...].

15 Jornal do Commercio. Ano XXXIV, n. 9958, 11 de fevereiro de 1887.

16 Peters emprega ora o termo negro, ora o termo preto, ora o termo africano para os nativos. Mantivemos, na tradução, a designação original.

17 Die afrikanische Arbeiterfrage (1901). In: PETERS, C. Gesammelte Schriften. Berlin: 1941. p. $415-419$ 
A América fechou a porta para eles, e dá para se compreender, pois na Rússia, mais do que em qualquer outro lugar, eles mantiveram sua cultura. [...] Eles poderiam, no entanto, ocupar uma boa região da África para nós ${ }^{18}$. (grifos nossos)

Um outro exemplo nos vem da Sociedade Colonial da África do Sudoeste: de autor desconhecido, o documento defende os castigos físicos aplicados aos nativos, pois, como crianças que resistem à escola, eles precisam ser disciplinados. Ademais, afora os bosquímanos e os hotentotes, os demais aceitam trabalhar para os brancos. Nesta região, cujo sucesso do empreendimento é inquestionável e exemplar, os nativos não têm direitos políticos; são representados por comissários brancos. Eles moram em reservas e terras sob a condição de não serem rebeldes.

O chefe da tribo é responsável pela ordem da reserva; e se tudo corre bem, ele ganha um salário como funcionário público. As reservas têm bons locais de trabalho, mas há uma falha: propiciam a que os nativos regridam ao antigo desleixo. Por isso, compartilhar estas reservas com os brancos seria um equívoco. E há outro risco: que a reserva seja açambarcada, donde a necessidade que o direito à propriedade não lhes seja concedido ${ }^{19}$.

Um outro conjunto de documentos aponta favoravelmente para o exemplo da África do Sul. Segundo Carl Peters, por exemplo, este é um país exemplar quanto ao tratamento conferido aos nativos e isso não pode ser modificado ${ }^{20}$. A África do Sul não pode se pautar no exemplo do Canadá ou da Austrália (de separação do território por etnias), muito menos no exemplo do Brasil ou do México, onde ocorreu a miscigenação.

Os negros não têm direito ao solo sul-africano, pois os boeurs o conquistaram pela lei do mais forte. Eles não entendem por que devem tratar

18 Ibidem, p. 322. Temos de levar em conta que a experiência de assentamento de judeus na África não era inovadora. À época da corrida do ouro, eles foram para lá e viraram financistas. No caso em questão, tratava-se de judeus muito pobres, e que poderiam se estabelecer como colonos.

$19<$ www.jaduland.de/Kolonien/ddk/probleme.html>. Documento datado de 1910, pesquisa realizada em 9 de outubro de 2009.

20 Die Rassenfrage in Südafrika (1911). In: PETERS, C. Gesammelte Schriften. Berlin: 1941. p. $443-446$. 
um vencido de maneira diferente a de um vencido. Afinal, os zulus, quando dominaram outros negros, fizeram deles escravos ou os exterminaram. Por que os boeurs deveriam agir de maneira diferente?

O raciocínio de Peters, neste tocante, obedece, segundo ele mesmo, à lógica da economia política: são 5 milhões de negros, não há como colocar todos estes habitantes em reservas. Além disso, 200 mil negros trabalham na indústria e, enquanto seu salário é de 3 libras por mês, a um branco remunera-se 6 a 10 libras por semana (estas proporções são válidas também para as atividades rurais). Logo, se este país quiser se industrializar, ele não pode dispensar a mão de obra preta.

E se, por acaso, dada a proximidade entre brancos e negros, ocorrerem casamentos mistos, a branca é tratada como uma proscrita, como uma leprosa $^{21}$, motivo pelo qual isso raramente acontece.

Peters não é o único, obviamente, a enxergar a miscigenação como a principal ameaça ao projeto colonial: também Frieda von Bülow, que, como dissemos, preparava moças brancas para casarem-se com os colonizadores. Ela afirmava, inclusive, que a experiência nas colônias fortalecia a raça branca, pois estes homens tinham de conter seus instintos sexuais, depositando todas as suas energias no trabalho e na sua missão ${ }^{22}$.

Dentre todos os exemplos que poderíamos citar e que refletem a intensificação do racialismo como elemento estruturante da política colonial, eu gostaria agora de ater-me ao genocídio do povo herrero. Como já mencionamos, tratou-se de um massacre que extinguiu $80 \%$ da população nativa (cerca de 80 mil pessoas), além da prática da tortura e do abuso sexual das mulheres sobreviventes, ocorrido na região da África do Sudoeste, hoje Namíbia, para onde foram, a partir de 1884, 12 mil alemães. Em 1904, quando os herreros se rebelaram contra a exploração a que iam sendo submetidos, bem como ao enclausuramento em reservas cujo solo era praticamente infértil, foram assassinados ou empurrados para o deserto.

Este massacre calou fundo na memória dos nativos, tanto assim que, em 1914, quando os alemães pretenderam recrutar tropas nativas para combater na guerra, de 50 mil nativos passíveis de recrutamento apenas 6 mil foram empregados. Os demais negaram-se a participar - ainda que para 
tanto pudessem ganhar algum dinheiro -, não poucos, devido à crueldade dos castigos aplicados para a observância da disciplina, acabavam por passar para o lado dos inimigos ${ }^{23}$.

Outro dado importante: esta guerra custou 585 milhões de marcos ao governo alemão, bem como a morte de 1.500 soldados. Isso significou, em termos financeiros, que a região provocou mais perdas do que ganhos. Ao todo, a importação de produtos desta colônia não somou senão $0,5 \%$ de todos os produtos do Reich ${ }^{24}$. Dez anos depois, quando a Primeira Guerra se inicia, as tropas alemãs capitularam em apenas 10 meses.

Mais impressionante ainda é a declaração do comandante do ataque, o General Lothar von Trotha. A despeito da oposição parlamentar, não hesitou em alardear nos jornais a sua posição:

Eu, o grande general dos soldados alemães, envio esta carta ao povo herrero; vocês não são mais súditos da Alemanha; vocês mataram e roubaram, mutilaram orelhas e narizes de soldados e cortaram outras partes do corpo, e querem agora por covardia desistir de lutar. Eu digo ao povo: aquele que entregar no meu posto um dos capitães como prisioneiro, receberá mil marcos, e quem trouxer Samuel Maharero, receberá 5 mil marcos. O povo herrero deve agora abandonar esta terra.

Quem não o fizer, meto-lhe a cacetada para fora. Dentro das fronteiras alemãs, todos os herreros, quer tenham espingardas ou não, quer tenham criatório ou não, serão abatidos com arma de fogo, não recebo mais crianças ou mulheres, fujam elas com seu povo ou perecerão. $[\ldots]^{25}$.

\section{E, depois deste pífio triunfo, pondera sobre como encerrar defini- tivamente o conflito:}

Pergunto-me agora como terminar a guerra com os herreros. $\mathrm{O}$ ponto de vista do governador, também o ponto de vista de antigos africanos brancos, e o meu ponto de vista estão em completo desacordo. O governador quer negociar por algum tempo com os

23 ARRIFES, Marcos Fortunato. A Primeira Grande Guerra na África Portuguesa: Angola e Moçambique. Lisboa: Cosmos, 2004. p. 232-233.

24 KÖLN, Andreas. Massaker in der Omahecke. In: Geoepoche, n. 12, s/d., p. 145.

25 Ao comando das tropas de ocupação, 2/10/1904. Disponível em: <www.deutscheschutzgebiete.de/von_trotha.html>. 
herreros, e pensa na nação Herrera como necessária como mão de obra para o futuro desenvolvimento do país. Eu penso que uma nação como esta deve ser totalmente aniquilada, ou se isso não for possível, devem eles serem expelidos para fora do país ${ }^{26}$.

Sem dúvida, para além do ódio e de sua demasiada sinceridade nas palavras, von Trotha reage a um fato visto como inusitado: ali, o que havia ainda do acalentado mito do bom selvagem, ou da imagem do nativo como uma criança ávida por aprender novos hábitos de sociabilidade e de trabalho, acabava por esvair-se. Os herreros quase derrotaram o comandante Leutwein (que precedeu von Trotha), resistiram por dois anos a soldados que portavam armas infinitamente mais eficazes do que as suas e eram uma nação, e esta nação, assim experimentada, precisava desaparecer para que outra surgisse: uma nação de arianos na África.

Como já mencionamos, a população que não foi exterminada no que ficou amplamente conhecido por fotos, jornais e declarações oficiais como "O Massacre em Ohmeke", pereceu de outra forma, sendo presos em campos de concentração.

Os corpos masculinos serviram como base de pesquisa para diversos cientistas, dentre eles Eugen Fischer, antropólogo que seria responsável pelas políticas eugenistas na Alemanha nazista e que teria entre seus alunos o médico Joseph Mengele.

Além dos crânios, segundo Robert Gordon ${ }^{27}$, Eugen Fischer pesquisou também a genitália masculina dos herreros, concluindo que aqueles que eram miscigenados não tinham uma completa ereção; por isso, eram incapazes de aprender técnicas de agricultura e do criatório. Tanto ele como outros cientistas realizaram diversas comparações entre as características físicas dos herreros e dos judeus - ambos vistos como possuidores de uma sexualidade exacerbada, donde também, como os ciganos, sua tendência ao nomadismo, sinônimo de vagabundagem. Concluem ainda que ambos os grupos étnicos procedem da "raça camita", um ramo dos semitas, e que todos, ao fim e ao cabo, são produto da miscigenação. Daí a necessidade de isolá-los, exterminá-los ou pelo menos, impedir-lhes a procriação.

2001. p. 11.

26 Apud MAMDANI, Mahmood. When victms bekome killers. Princeton: University Press,

27 The rise of the Bushman penis: german, genitalia and genocide. African Studies, v. 57, n. 1, p. 27-54 


\section{Conclusão}

Feita esta análise sobre alguns aspectos do Imperialismo alemão, gostaríamos de realizar algumas considerações que favoreçam a compreensão das possíveis conexões entre a experiência colonial e o nacional-socialismo, principal objetivo deste artigo.

A primeira delas diz respeito à difusão das práticas imperialistas na Europa como um todo, espraiadas em inúmeros panfletos de propaganda, literatura de ficção, artigos jornalísticos e textos pseudocientíficos. A circularidade destas ideias comprova, a meu ver, aquilo que Hannah Arendt afirmou sobre a burocracia colonial como prefiguração dos governos totalitários e protototalitários.

Segundo a autora,

O que aconteceu foi que os negociantes de mentalidade imperialista foram seguidos por funcionários desejosos de deixar "o africano permanecer africano", enquanto um bom número de outros, apegados ainda ao que Harold Nicolson chamou certa vez "ideias de infância", queria ajudá-los "a tornar-se um africano melhor" - fosse lá o que fosse que isso pudesse significar. Mas de nenhum modo estavam dispostos a aplicar o sistema administrador e político do seu país para governar as populações atrasadas e unir realmente as vastas possessões da Coroa britânica à nação inglesa ${ }^{28}$.

$[\ldots]$

Os imperialistas nunca se haviam conformado com o fato de o governo colonial da Índia ter de justificar a sua existência e a sua política perante a opinião pública da Inglaterra; esse controle impossibilitava lançar mão daquelas medidas de massacres administrativos que, imediatamente após a primeira guerra mundial, haviam sido ocasionalmente experimentadas em toda a parte como meio radical de pacificação [...] hostilidade semelhante prevaleceu na Alemanha entre os representantes nacionais e os administradores coloniais da África. Em 1897, Carl Peters foi removido do seu posto no Sudeste Africano alemão e teve de se demitir do serviço público devido a atrocidades ali cometidas contra os nativos. O mesmo sucedeu a Zimmerer. Em 1905 os chefes tribais dirigiram suas queixas pela primeira 
vez ao Reichstag, de forma que, quando os administradores coloniais os aprisionaram, o governo alemão interveio ${ }^{29}$.

Esta tensão - entre o governo e os colonizadores - permaneceria, como procuramos demonstrar, ao longo de todo o período em que alemães administraram possessões na África. Mas, a partir de 1914, quase todos precisaram regressar, mesmo que a contragosto, ao seu país. Ali, como já faziam desde o início do século, prosseguiram com sua propaganda, o que influenciaria sobremaneira a opinião pública, com mensagens que atingiram, seguramente, Adolf Hitler, também ele leitor de Carl Peters, Frieda von Bülow e Eugen Fischer.

Entretanto, a circularidade das doutrinas racistas e sobre as enormes possibilidades de enriquecimento com a exploração de territórios estrangeiros não se deu apenas na Alemanha: belgas, ingleses, portugueses, sul-africanos, holandeses, franceses, apesar de concorrentes entre si, sorviam das experiências uns dos outros, o que potencializava suas estratégias de dominação.

Finalmente, o tema do genocídio. Afirmamos que o genocídio herrero foi precedido por outras formas de dominação e humilhação, as quais procuramos entender como o controle do corpo de pessoas cada vez mais estigmatizadas como raça. Neste tocante, um dos experimentos mais escabrosos (até então inimaginável mesmo por Lombroso) foi aquele realizado por Eugen Fischer, que estudou a genitália de pelo menos 800 herreros como determinante do comportamento humano, donde, provavelmente, a ideia de esterilização em massa pode ter se transformado em algo aceitável.

Maus-tratos, açoites, tortura e assassinatos, nesta ordem, iam se tornando cada vez mais frequentes e "normais". Por seu lado, também os nativos pareciam estar aprendendo as mesmas técnicas de brutalidade de seus opressores, pelo menos se levarmos em conta as palavras de von Trotha, que afirmou terem os herreros mutilado os corpos de seus oponentes alemães.

Isso nos conduz à reflexão de Mahmood Mandami, para quem o genocídio tem a sua própria história, a sua própria geografia e a sua popularidade. Conquanto irracional, ele não pode ser considerado uma coisa de governo: para o autor, todo o genocídio, em algum nível, conta com o apoio e a participação popular ${ }^{30}$.

29 Ibidem, p. 163.

30 MAMDANI, op. cit., p.12 et seq. 
O impulso a esta forma de agressividade pode ser explicado pelo sentimento de autodefesa, pelo desejo de afirmação de sua vida como a única legítima de ser vivida ali e naquele instante; logo, mesmo de maneira falseada ou ilusória, cria-se uma plena convicção de que se é o único e genuíno nativo e o outro, colonizador.

São estas as palavras de von Trotha aos herreros: "vocês não ficam mais em solo alemão". Foram palavras muito semelhantes a estas que levaram ao extermínio de judeus e ciganos: eles exploravam a Alemanha, eles poderiam contaminar a raça ariana, eles eram descendentes (por que não?) de africanos.

\section{FIGURA 3 - HERREROS SENDO LEVADOS AO CAMPO DE CONCENTRAÇÃO.}

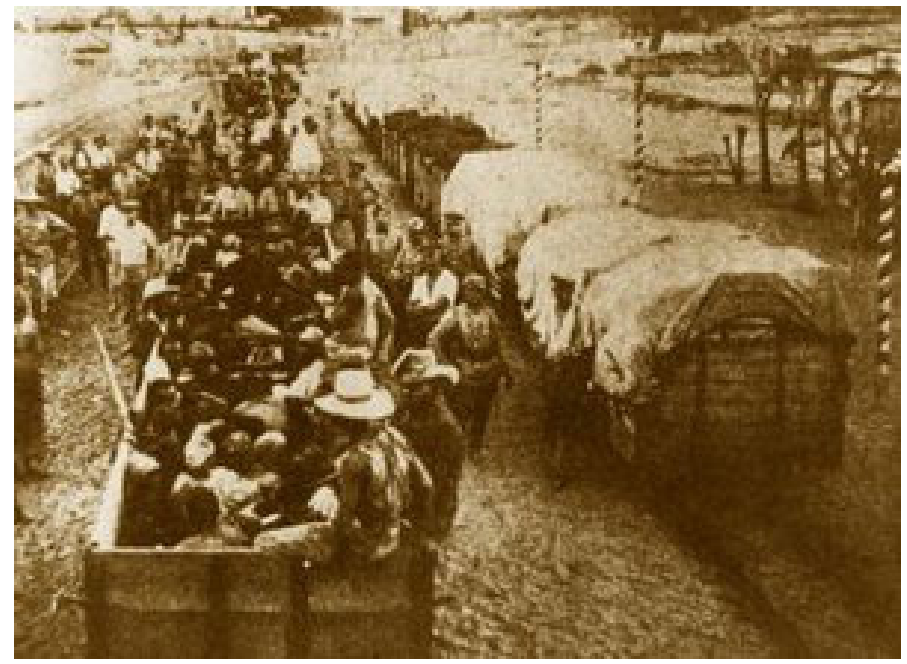

FONTE: www.ezakwantu.com/gallery/herrero.

Pesquisa realizada em 15 de outubro de 2009. 
FIGURA 4 - CAMPO DE CONCENTRAÇÃO NA ÁFRICA DO SUDOESTE, HOJE NAMÍBIA.

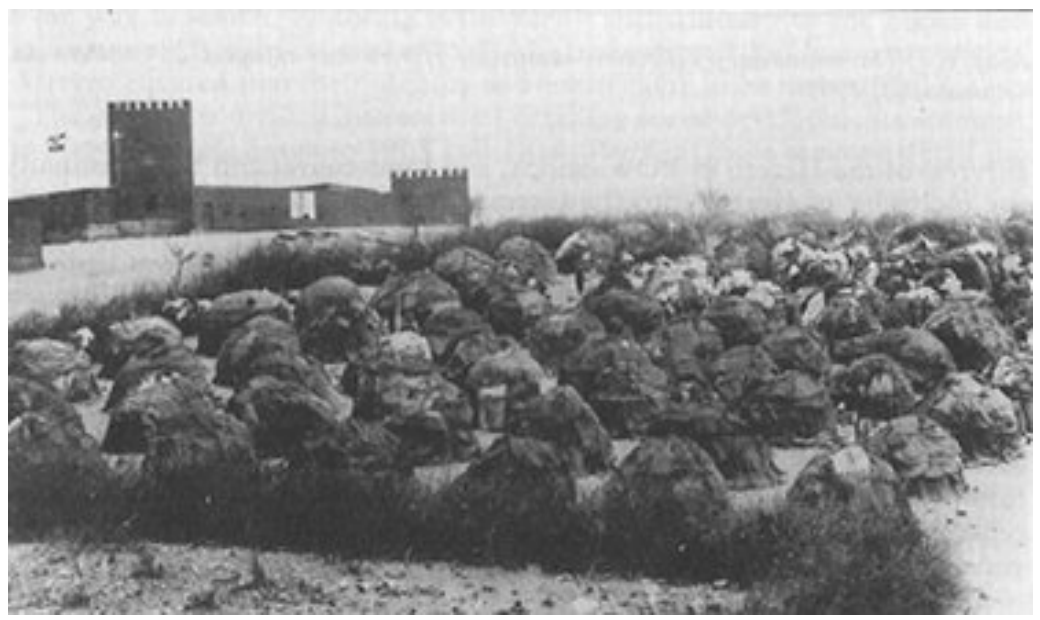

FONTE: www.ezakwantu.com/gallery/herrero

Pesquisa realizada em 15 de outubro de 2009. 
FIGURA 5 - FOTOS DE HERREROS UTILIZADAS POR EUGEN FISCHER PARA O ESTUDO DOS EFEITOS DA MISCIGENAÇÃO (AO TODO, 2.200 FOTOS).
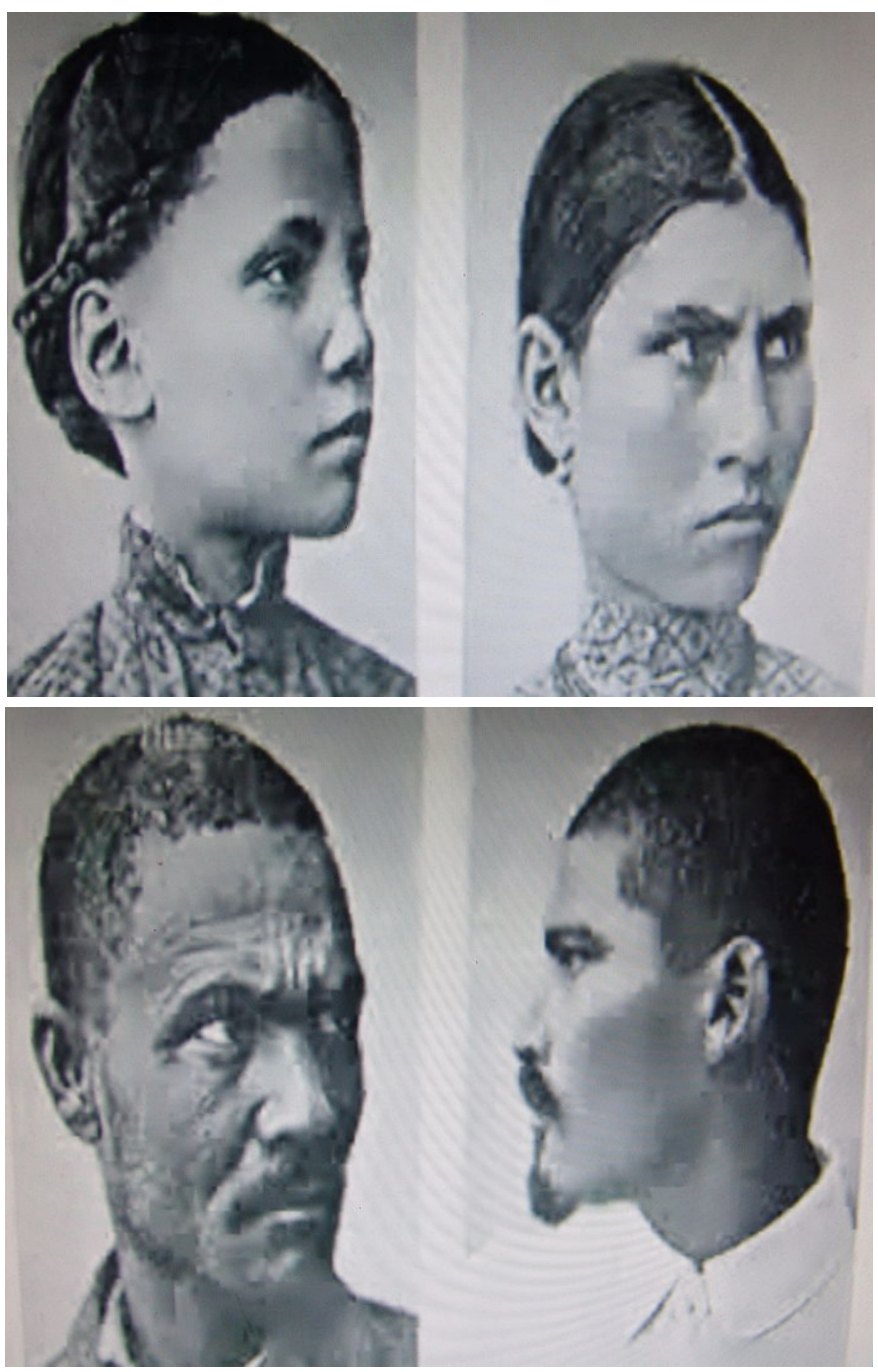

FONTE: www.ezakwantu.com/gallery/herrero

Pesquisa realizada em 15 de outubro de 2009. 
FIGURA 6 - CARTÃO POSTAL, CUJA LEGENDA, EM TRADUÇÃO LIVRE, É A SEGUINTE: "UM CAIXÃO COM CRÂNIOS DE HERREROS FOI RECENTEMENTE LACRADO E ENVIADO AO INSTITUTO PATOLÓGICO DE BERLIM, ONDE DEVEM SER UTILIZADOS PARA MENSURAÇÕES CIENTÍFICAS. AS MULHERES HERREROS REMOVERAM A CARNE, A PELE E O CABELO DESTES CRÂNIOS UTILIZANDO CACOS DE VIDROS. OS CRÂNIOS SÃO DE HERREROS MORTOS EM AÇÃO OU PRESOS".

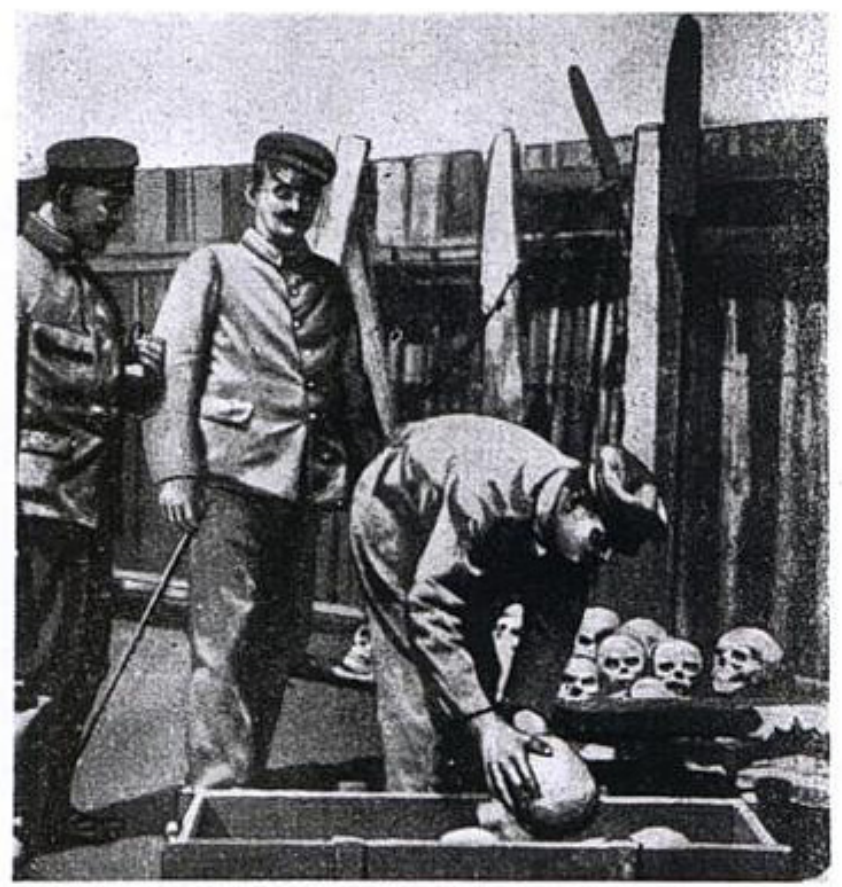

Cine aife uit Sercroiuabert

tourbe fatratt

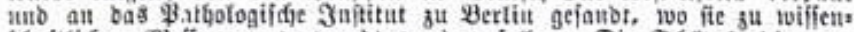

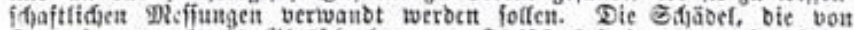

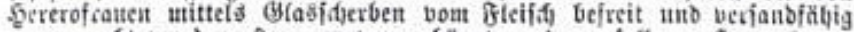
gensafit rourben, framuen vou gelgängten ober gefalfesten gereros.

FONTE: www.ezakwantu.com/gallery/herrero.

Pesquisa realizada em 15 de outubro de 2009.

Recebido em 08/10/2009. Aprovado em 13/12/2009. 